\title{
Effects of Nerve Growth Factor on Differentiation of Muscle Spindles Following Nerve Lesion in Neonatal Rats
}

\author{
S. Sekiya, S. Homma, Y. Miyata, and M. Kuno \\ National Institute for Physiological Sciences, Okazaki 444, Japan
}

Central synaptic function of Group Ia sensory fibers has been shown to be enhanced by daily applications of NGF in neonatal rats. In the periphery, Group Ia sensory fibers are known to trigger the differentiation of muscle spindles. In the present study we examined, in neonatal rats, whether daily NGF treatment affects the number or structure of spindles formed in muscle whose nerve has been crushed. The results show that 25-35 d after nerve crush, de novo supernumerary spindles were formed by treatment with NGF in the temporarily denervated muscle. The number of spindles in the corresponding muscle on the contralateral, intact side was not affected by NGF treatment. Following nerve crush alone, the mean number of spindles in the muscle was not significantly different from the normal value. It is suggested that treatment of neonatal rats with NGF may facilitate the outgrowth of excessive peripheral collaterals of regenerating Group Ia sensory fibers, which, in turn, contributes to the formation of de novo spindles as a result of interaction with myotubes.

During development, muscle spindles in the rat become discernible about $3 \mathrm{~d}$ before birth, and the formation of mature spindles is complete within 2-3 weeks after birth (Landon, 1972; Milburn, 1973; Zelená, 1957). When skeletal muscles are denervated in newborn rats, the muscle spindles fail to differentiate further and disintegrate in a few days (Zelená, 1957; Zelená and Hnik, 1963). Even in muscles reinnervated after nerve crush performed at birth, the number of spindles is reduced and the surviving spindles are small and atypical in structure (Hnik and Zelená, 1961; McArdle and Sansone, 1977; Werner, 1973a, b). However, section of the ventral roots (de-efferentation) in neonatal rats does not interfere with normal development of muscle spindles (Zelená and Soukup, 1973, 1974). Thus, sensory innervation appears to be crucial for the development and maintenance of muscle spindles. In perinatal rats, the first axons to make contact with intrafusal fibers are Group Ia sensory fibers (Milburn, 1973; Zelená, 1957). Therefore, it has been suggested that the differentiation of muscle spindles is triggered by Group Ia fibers and that the arrest of spindle development following denervation in newborn rats results from the loss of sensory innervation (Zelená, 1976).

The preceding study (Miyata et al., 1986; also see Kuno et al., 1985) showed that monosynaptic excitatory postsynaptic potentials (EPSPs) evoked in spinal motoneurons by muscle afferent volleys are strikingly depressed following crush of the muscle nerve in neonatal rats and that this synaptic depression

Received Oct. 7, 1985; revised Dec. 9, 1985; accepted Dec. 17, 1985.

We wish to thank Dr. Masaharu Ogawa for detailed instructions in preparing NGF and its antiserum. We are also grateful to Drs. Shinichiro Hori and Kyozo Hayashi for providing us with purified NGF and its antiserum in an early stage of the present study.

Correspondence should be sent to M. Kuno, Department of Physiology, Kyoto University Faculty of Medicine, Kyoto 606, Japan.

Copyright (c) 1986 Society for Neuroscience $0270-6474 / 86 / 072019-07 \$ 02.00 / 0$ is partially reversed by daily treatment with NGF. Thus, the central synaptic function of Group Ia sensory fibers in neonatal animals appears to be influenced by exogenous NGF under certain conditions. The mechanism underlying enhancement of the EPSPs by NGF is not clear. It is known that crush of the peripheral nerve in neonatal rats results in massive cell death of the sensory neurons (Bondok and Sansone, 1984; Yip and Johnson, 1984; Yip et al., 1984). However, NGF treatment does not prevent the cell death of large sensory neurons (Miyata et al., 1986). Therefore, there is little doubt that central terminals of Group la fibers undergo some alterations in response to NGF, either increasing transmitter release or producing sprouting. The purpose of the present study is to examine whether the peripheral segments of Group Ia fibers are also responsive to exogenous NGF. For this purpose, a muscle nerve was crushed in neonatal rats, and morphometric observations made of spindles in the reinnervated muscle with or without NGF treatment. The results show that de novo supernumerary spindles are formed in the temporarily denervated muscle following treatment with exogenous NGF.

\section{Materials and Methods}

Surgical procedures were exactly the same as those described in the previous paper (Miyata et al., 1986). Wistar rats were anesthetized with ether the day after birth, and the nerve to the medial gastrocnemius (MG) muscle was crushed with a Dumont forceps at the bifurcation point near its entry to the muscle in the left hind leg. The intact, contralateral MG muscle served as a control.

After a postoperative period of 25-35 d, the animal was ancsthetized by an intravenous injection of pentobarbital sodium $(50 \mathrm{mg} / \mathrm{kg})$. The MG muscle was excised from each leg and fixed in $10 \%$ formalin. The specimen was dehydrated by alcohols with graded concentrations and embedded in paraffin. Serial transverse sections were cut at $8 \mu \mathrm{m}$ and mounted on glass slides. The sections were stained with hematoxylin and eosin. Some alternate sections were also observed with Bodian's stain or Masson-Goldner's stain. Quantitative measurements of the diameters of the spindles and intrafusal fibers were made by digitizing tablet combined with light microscopy at a magnification of $450 \times$.

The procedures for preparing NGF and its antiserum, as well as their daily administration programs, were the same as those employed in the previous paper (Miyata et al., 1986). In brief, $2.5 \mathrm{~S} \mathrm{NGF,} \mathrm{purified} \mathrm{from}$ submaxillary gland of male mice, was intraperitoneally injected every day for 1 weck from the day after birth at a dose of $2 \mu \mathrm{g} / \mathrm{gm}$ body wcight. Thereafter, the same dose of NGF was given every other day until the day before the animal was sacrificed. The antiserum against the $2.5 \mathrm{~S}$ mouse NGF was subcutaneously injected daily for 1 week from the day after birth at a dose of $10 \mu \mathrm{l} / \mathrm{gm}$ body weight. After a 1 week pause, the same dose of the antiserum was given again for 7 consecutive days.

\section{Results}

The number of spindles

In 5 rats, the MG nerve was unilaterally crushed the day after birth, and the number of spindles in the muscle was compared with that in the intact, contralateral MG muscle 25-35 d later. One of the $5 \mathrm{MG}$ muscles on the control side was discarded 

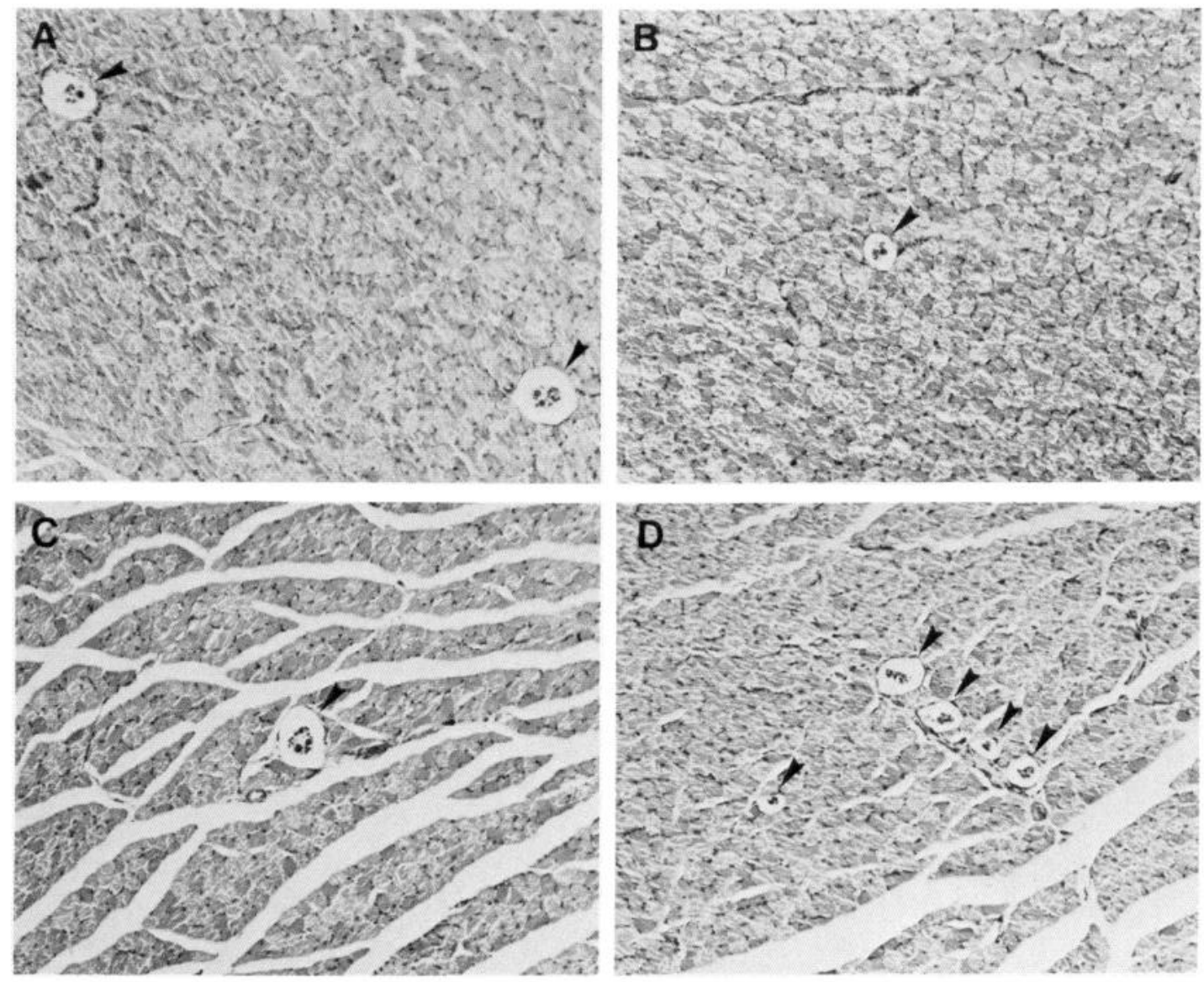

Figure 1. Muscle spindles in transverse sections of the MG muscles under different experimental conditions. Hematoxylin eosin, 100×. Spindles are indicated by arrowheads. $A$, On the control, unoperated side; $B$, on the nerve-crushed side from the same animal. $C$, On the control, unoperated side in an NGF-treated rat; $D$, on the nerve-crushed side in the same NGF-treated animal.

since a small piece of the tissue was lost during preparation. In agreement with Werner (1973b), the control MG muscle contained 18-20 spindles, with a mean of $19.3 \pm 1.0$ (this gives the mean and SD). On the operated side, one muscle contained only 9 spindles, whereas another muscle had 26 spindles. The number of spindles observed in 3 other experimental muscles ranged from 19 to 21 . Thus, as reported by Werner (1973b; also see Zelená and Hnik, 1963), the number of spindles could increase or decrease following nerve crush in neonatal rats. However, the mean number of spindles in the MG muscle on the operated side $(18.8 \pm 6.2)$ was not significantly different from that on the control side.

The MG muscle was also examined on the day after birth in 3 unoperated rats. The mean number of spindles in these muscles $(18.8 \pm 2.2)$ was similar to that observed in the control MG muscles 26-36 d after birth (Fig. 2, Newborn). Therefore, it seems clear that all the muscle spindles are already formed by the time of nerve crush.

The most striking change was observed in the number of spindles on the operated side in NGF-treated animals, although the number of spindles in the muscle on the control side was not affected. Figure 1 shows muscle spindles observed in the MG muscles on the control $(A)$ and operated $(B)$ sides in a rat without NGF treatment, and on the control $(C)$ and operated (D) sides in an NGF-treated animal. While only 1 or 2 spindles were usually seen in each cross section (Fig. $1, A-C$, arrowheads), a section obtained from the muscle on the operated side in the NGF-treated animal (Fig. 1D) contained 5 spindles. Four of the 5 spindles were apparently clustered along a nerve branch.
Figure 2 summarizes the mean number of spindles per muscle under different experimental conditions. In 5 rats treated with $\mathrm{NGF}$, the number of spindles on the crushed side ranged from 29 to 49 (mean, $38.8 \pm 8.0$ ), while that on the control side ranged from 20 to 24 (mean, $21.3 \pm 1.9$ ). This difference was highly significant $(p<0.005)$. The mean number of spindles observed in 3 unoperated rats injected with the antiserum to NGF was $20.0 \pm 1.0$. Thus, only those muscles whose nerves had been crushed on the day after birth in NGF-treated animals showed a clear change in the number of spindles.

\section{The size of muscle spindles}

Muscle spindles observed on the nerve-crushed side appear to be atrophic even in NGF-treated animals, when compared to those on the control side (Figs. 1 and 5). Spindle size was quantified in terms of diameter and length. For the former, the maximal diameter of the spindle capsule measured at the equatorial region in serial cross sections was used. Figure $3 A$ shows the distribution of spindle diameters measured in the MG muscles on the control (open circles) and operated (filled circles) sides. The distribution illustrated in Figure $3 B$ is similarly obtained from NGF-treated rats. The mean diameter on the control side (Fig. $3 A)$ was $52 \pm 11 \mu \mathrm{m}(n=91)$, whereas that on the operated side was $26 \pm 12 \mu \mathrm{m}(n=94)$. A similar significant difference in NGF-treated animals was also observed between the control $(48 \pm 10 \mu \mathrm{m} ; n=97)$ and operated $(26 \pm 10 \mu \mathrm{m} ; n=186)$ sides. Thus, the NGF treatment did not significantly affect the spindle diameter on both the control and operated sides.

The length of a spindle was estimated by measuring the dis- 


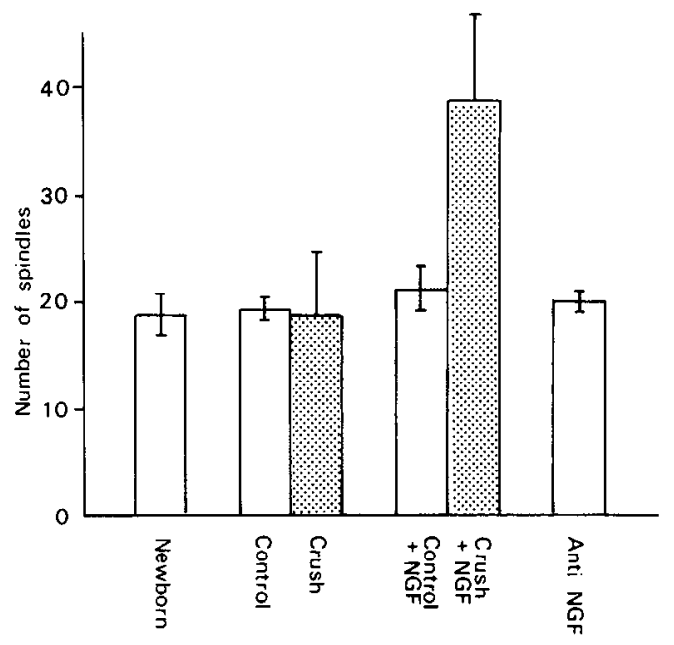

Figure 2. The mean number of spindles in the MG muscle observed under different experimental conditions. Vertical bars, SDs. Newborn results obtained from normal rats on the day after birth. Shaded columns are results obtained from the muscles on the operated side (Crush) with $(+N G F)$ or without NGF treatment; their paired open columns are those observed in the muscles on the control side of the same animals. Anti $N G F$ results were obtained from unoperated rats chronically injected with the antiserum to NGF.

tance between the 2 ends of the spindle at which the periaxial space disappeared. Figure 4 shows the distributions of spindle lengths. The mean length on the operated side (Fig. $4 A$, filled circles; $390 \pm 250 \mu \mathrm{m} ; n=93$ ) was significantly shorter than that on the control side (open circles; $940 \pm 240 \mu \mathrm{m} ; n=90$ ). A significant difference in spindle length in NGF-treated rats was also found between the control $(930 \pm 300 \mu \mathrm{m} ; n=92$; Fig. $4 B$, open circles) and operated $(360 \pm 170 \mu \mathrm{m} ; n=188$; filled circles) sides.

In 3 unoperated rats injected with the antiserum to NGF, the mcan diamcter $(54 \pm 8 \mu \mathrm{m} ; n=57)$ and length $(890 \pm 190 \mu \mathrm{m}$; $n=55$ ) of spindles of the MG muscles were comparable to the values observed in the normal, control muscles.

\section{Alterations of intrafusal fibers}

The majority of mature spindles in the rat are known to contain 2 nuclear bag and 2 nuclear chain fibers (Marchand and Eldred, 1969; Werner, 1973b). This was confirmed in the present study. In the MG muscles on the intact side, $80 \%$ of the spindles examined had 2 nuclear bag and 2 nuclear chain fibers. This ratio remained unchanged in the innervated $\mathrm{MG}$ muscles of the animals treated with NGF $(84 \%)$ or with its antiserum $(84 \%)$.

Figure 5 shows some examples of nuclear bag (arrows) and nuclear chain (arrowheads) fibers. Spindles on the control side typically contained 2 bag and 2 chain fibers with $(D)$ or without (A) NGF treatment. The majority of spindles on the nervecrushed side contained fewer intrafusal fibers (Fig. 5, B, C, F) whether the animal was treated with NGF or not. Occasionally, a spindle on the operated side had many intrafusal fibers. In such cases, intrafusal fibers appeared to be clustered in separate groups (Fig. 5E), which suggests that multiple spindles might be fused or ensheathed with a new capsule (see below; Fig. 8). Figure 6 summarizes the distribution of the intrafusal fibers contained in each spindle under different experimental conditions. It seems clear that in the presence (Fig. $6 B$ ) or absence $(A)$ of NGF, the majority of muscle spindles on the operated side contain only 1 or 2 intrafusal fibers (filled circles), in contrast to those on the control side (open circles).

Figure 7 shows the distribution of diameters of intrafusal fibers measured at the equatorial region. On the nerve-crushed
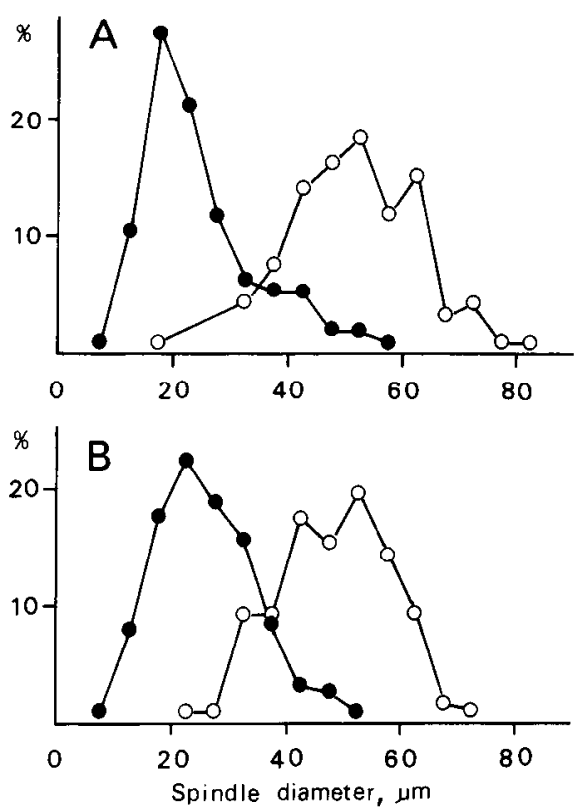

Figure 3. Distributions of the maximal diameters of spindle capsules measured at the equatorial region. Open circles show results obtained from the MG muscles on the control side; filled circles, from the MG muscles whose nerves had been crushed the day after birth. Observations were made on animals with $(B)$ or without $(A)$ NGF treatment.

side, many intrafusal fibers showed no clear nuclear profile that distinguished between the nuclear bag and chain types (Schiaffino and Pierobon Bormioli, 1976; Werner, 1973b), although the 2 types could be identified in some spindles (Fig. 5). There-
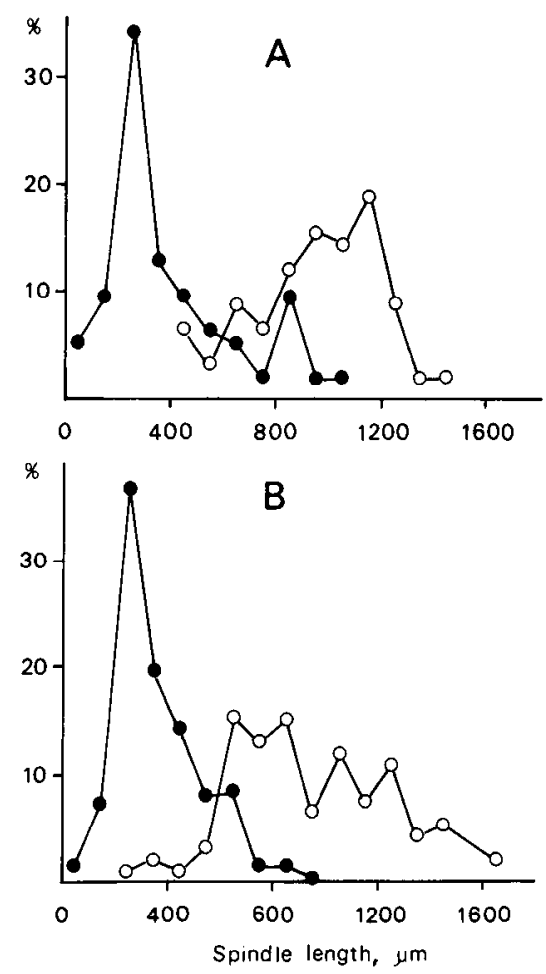

Figure 4. Distributions of spindle lengths observed under different experimental conditions. Open circles show results from the MG muscles on the control side; filled circles, from the MG muscles whose nerves had been crushed the day after birth. Observations were made on animals with $(B)$ or without $(A)$ NGF treatment. 



Figure 5. Intrafusal muscle fibers of spindles in transverse sections of the MG muscles under different experimental conditions. Hematoxylin eosin, $500 \times . A-C$, From an animal without NGF treatment. $D-F$, From an NGF-treated animal. $A$ and $D$, From the control side; $B, C, E$, and $F$, from the nerve-crushed side. Arrows indicate bag fibers; arrowheads, chain fibers.

fore, the diameters of intrafusal fibers were measured separately for the nuclear bag and chain types on the control side only. The mean diameters of nuclear bag and chain fibers were $9.1 \pm$ $1.2 \mu \mathrm{m}(n=138)$ and $5.7 \pm 0.9 \mu \mathrm{m}(n=136)$, respectively, on the control side. Thus, their diameter distribution showed 2 modal peaks (Fig. $7 A$, open circles). In NGF-treated rats (Fig. $7 B)$, the mean diameters of nuclear bag $(9.1 \pm 1.5 \mu \mathrm{m} ; n=173)$ and chain $(5.7 \pm 0.9 \mu \mathrm{m} ; n=173)$ fibers on the control side were virtually identical with those observed in the animals without NGF treatment, although the expected 2 modal peaks were somewhat obscure (Fig. $7 B$, open circles). The diameter distribution of intrafusal fibers on the nerve-crushed side (filled circles) was also similar in the animals with (Fig. $7 B$ ) or without $(A)$ NGF treatment. In both cases, the ratio of the group of intrafusal fibers with a small diameter to the group with a large diameter increased, showing a unimodal distribution with a skewness to the left. This suggests that preferential degeneration or atrophy of the bag fibers occurs in the temporarily denervated muscle. The bag fibers are also known to degenerate more rapidly than the chain fibers after devascularization of the muscle (Barker and Milburn, 1984).

In 3 unoperated rats injected with antiserum to NGF, the diameter distribution showed 2 modal peaks (Fig. $7 C$ ) which corresponded to the nuclear bag and nuclear chain fibers, respectively. The mean diameters of the nuclear bag $(9.9 \pm 1.4$ $\mu \mathrm{m} ; n=114)$ and nuclear chain $(6.1 \pm 0.8 \mu \mathrm{m} ; n=113)$ fibers were both about $10 \%$ larger than those observed on the control side in the animals treated or untreated with NGF. These differences were highly significant $(p<0.001)$. An increase in the diameter of intrafusal fibers was the only significant effect obtained by treatment with the NGF antiserum. The explanation for this effect remains uncertain.

\section{Extrafusal muscle fibers in the capsule}

In neonatal rat muscles reinnervated after temporary denervation, Werner (1973b) has observed "mixed" muscle fibers. These fibers have extrafusal characteristics at one pole and penetrate the spindle capsule, where they show morphological characteristics of intrafusal fibers. In the present study, an extrafusal fiber was observed within the capsule in 2 spindles on the operated side in NGF-untreated rats, and in 12 spindles on the operated side. Figure 8 gives an example of such spindles in an NGF-treated rat. At the equatorial region, a relatively large muscle fiber (Fig. 8B, arrow) was present in the capsule, in addition to a pair of clusters (arrowheads), each of which contained 2 intrafusal fibers. By serial cross section, this relatively large muscle fiber was found to leave the capsule at the proximal region of the spindle (Fig. $8 A$ ), as well as at the distal region (C). In the outside as well as inside of the capsule, the muscle fiber contained only a few nuclei, located immediately beneath the membrane, showing typical extrafusal fiber characteristics. Thus, this fiber appears to be an extrafusal fiber penetrating through the capsule, and different from the previously reported "mixed" fibers (Werner, 1973b). Similar extrafusal fibers were examined by serial section in the outside as well as inside of the capsule in 3 other spindles. In every case, the presumptive extrafusal fiber was found to leave the capsule near, but not at, the end of the capsule (Fig. $8 D$ ). In a particular example, illus- 


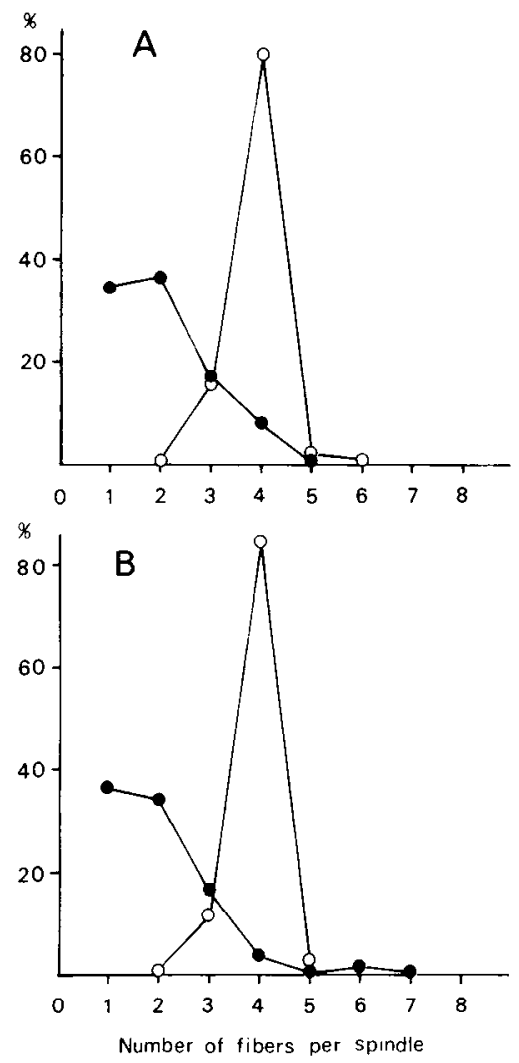

Figure 6. Distributions of the number of intrafusal fibers per spindle. Open circles, From the control side; filled circles, from the nerve-crushed side. Observations were made on animals with $(B)$ or without $(A) \mathrm{NGF}$ treatment.

trated in Figure 8, 2 spindles, each containing 2 intrafusal fibers (Fig. 8, $A, C$ ), seemed to be fused, being surrounded by a thicker capsule (Fig. $8 B$ ) through which an extrafusal fiber penetrated. Alternatively, these structures might have been ensheathed by a new capsule. The diameter of the extrafusal fiber within the capsule was, on the average, about $85 \%$ of that of the same fiber measured outside the capsule. Also, the extrafusal fibers that penctrated the capsulc were approximatcly $20 \%$ smaller than the neighboring extrafusal fibers that did not penetrate the capsule. Furthermore, when the type of intrafusal fibers could be identified by their nuclear profile, all the intrafusal fibers present in the spindles with an extrafusal fiber were exclusively the nuclear chain type. During development, the chain fibers are formed before the bag fibers (Barker and Milburn, 1984). It is possible that the spindles containing an extrafusal fiber are those newly developed following nerve crush.

\section{Discussion}

The most conspicuous result observed in the present study was that NGF treatment significantly increased the number of spindles formed in the muscle whose innervation had temporarily been interrupted on the day after birth. The number of spindles found under such conditions was almost twice as large as that observed in normal mature muscle. Therefore, there is little doubt that supernumerary spindles are formed de novo following reinnervation of the muscle in the presence of NGF. After crush of the MG nerve the day after birth, about $50 \%$ of the sensory neurons deriving from the muscle die (Miyata et al., 1986). The cell death of large sensory neurons induced by nerve crush was not affected by daily treatment with NGF (Miyata et al., 1986). In the absence of NGF, the mean number of spindles found in the nerve-crushed MG muscle was comparable to that seen in
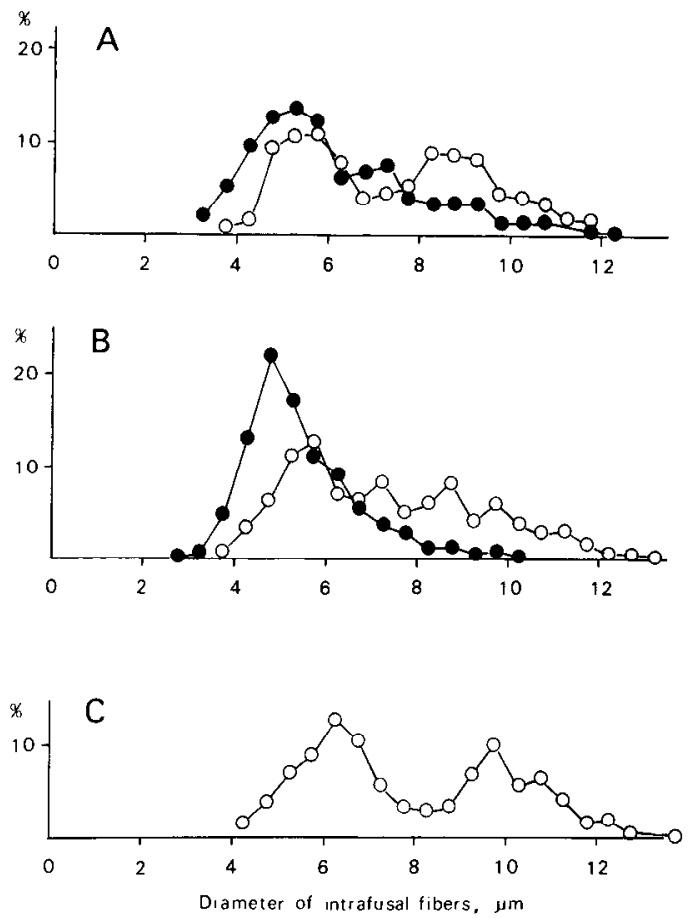

Figure 7. Distributions of the diameters of intrafusal fibers observed under different experimental conditions. $A$, From animals without NGF treatment; $B$, from animals treated with NGF; $C$, from unoperated rats injected with the antiserum to NGF. $A$ and $B$, Open circles, From the control side; filled circles, from the nerve-crushed side. Extrafusal fibers occasionally found in the spindle capsule (see Fig. 8) are not included in this figure.

the control muscle, in spite of the reduced number of muscle sensory neurons. Thus, the number of the reinnervating parent sensory fibers is not directly related to the number of spindles observed in the reinnervated muscle.

Out of 40 spindles examined with Bodian's stain in the nervecrushed MG muscle with NGF treatment, the reinnervating axonal branches were found to reach the capsules in 37 spindles. A similar profile was observed in 17 out of 19 spindles examined in the nerve-crushed MG muscle without NGF treatment. In the cat, the spatial distribution of spindles is closely related to the spatial pattern of intramuscular nerve branches (Barker and Chin, 1960). In NGF-treated rats, supernumerary spindles were also found to be in close proximity to intramuscular nerve branches (Fig. 1D). Thus, the number of intramuscular nerve branches appears to be a determinant of the number of spindles observed in the temporarily denervated muscle. McArdle and Sansone (1977) have shown that following crush of the sciatic nerve at birth, myotubes are present in up to $20 \%$ of the crosssectional area of the fast twitch muscle of the rat (see also Zelená and Hnik, 1963; Zelená, 1964, 1976). We hypothesize that treatment with NGF may facilitate the outgrowth of excessive peripheral collaterals of the axotomized sensory fibers, which, in turn, contributes to the formation of de novo spindles as a result of interaction with myotubes. It should be mentioned that, even in the absence of NGF, the formation of de novo spindles can be observed in some muscles reinnervated after nerve crush made at birth (Werner, 1973b; Zelená and Hnik, 1963). In the present study, a larger number of spindles than normal were also found in one of the temporarily denervated muscles without NGF treatment. Therefore, the presence of exogenous NGF is not a prerequisite to the formation of de novo spindles. Excessive collaterals of axotomized sensory fibers can be formed during reinnervation of the muscle in neonatal animals (Zelená and 

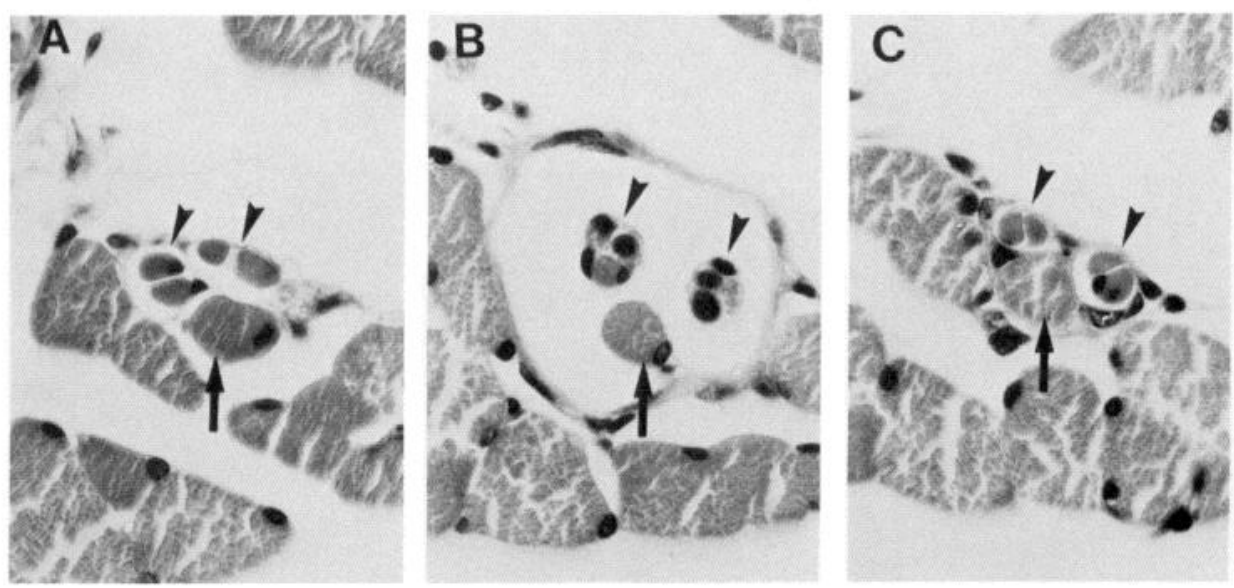

D

Figure 8. An extrafusal fiber penetrating the spindle capsule. Hematoxylin eosin, $660 \times$. Transverse sections of the MG muscle on the nervecrushed side in an NGF-treated rat. $A$, At the proximal region just outside the spindle; $B$, at the equatorial region of the spindle; $C$, at the distal region just outside the spindle. $D$, Schematic diagram showing the orientation of an extrafusal fiber penetrating the spindle capsule. Arrows indicate the extrafusal fiber; arrowheads, intrafusal fibers.

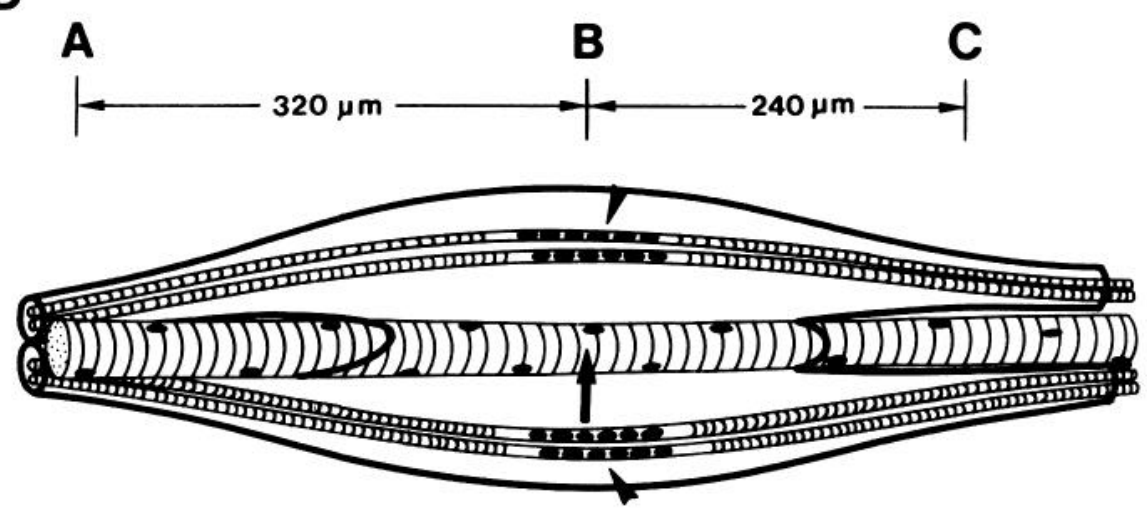

Hnik, 1963). Treatment with NGF may facilitate sprouting of sensory axonal collaterals under such conditions. Hopkins and Slack (1984) have shown that daily injections of NGF into neonatal mice causes prolific growth of sensory fibers in the muscle (see also Jenq et al., 1984). It is intriguing to note that some tissues release NGF following denervation (Ebendal et al., 1980, 1983; Korsching and Thoenen, 1985).

An avian muscle that normally lacks spindles has been demonstrated to form de novo spindles if the muscle is reinnervated by the nerve that normally supplies a muscle with spindles (Mackenson-Dean et al., 1981). This suggests that the formation of spindles depends upon the type of innervating fibers. Muscle spindles with a full complement of differentiated intrafusal fibers have been observed following de-efferentation in newborn rats (Zelená and Soukup, 1973, 1974). Therefore, sensory innervation is essential for both the development and differentiation of muscle spindles. In perinatal rats, Group Ia sensory fibers appear to be responsible for spindle development (Milburn, 1973; Zelená, 1957; but see Milburn, 1984, for kittens). It is likely that the formation of de novo supernumerary spindles is induced by excessive peripheral sprouting of axotomized Group Ia fibers in the presence of NGF. This bears a similarity to an increase in synaptic function at those synapses formed by central terminals of axotomized Group Ia fibers in the presence of NGF (Miyata et al., 1986). We conclude that both the central and peripheral segments of axotomized Group Ia neurons are responsive to exogenous NGF in neonatal rats.

As was the case for the central synaptic function of Group Ia sensory fibers (Miyata et al., 1986), the NGF antiserum had little effect on the postnatal development of muscle spindles, except for causing a slight increase in the diameter of intrafusal fibers. It should be noted, however, that the number of spindles in muscle with intact innervation was also unaffected by treatment with NGF. If NGF antiserum was applied following peripheral nerve crush, the number of spindles in the temporarily denervated muscle might be reduced. This possibility remains to be examined.

While supernumerary spindles were formed in the reinnervated muscle in the presence of NGF, virtually all the spindles were atypical in their morphological characteristics, as were those found in the absence of NGF. Schiaffino and Pierobon Bormioli (1976) have shown that, following denervation of muscle in neonatal rats, all the intrafusal fibers lack sensory terminals, although the reinnervating axons reach near or within the capsules. It is possible that the formation and subsequent differentiation of spindles may rely on different mechanisms: The former may be induced by the arrival of sensory fibers at the region abutting the target site, whereas the latter may require the formation of sensory terminals.

\section{References}

Barker, D., and N. K. Chin (1960) The number and distribution of muscle spindles in certain muscles of the cat. J. Anat. 94: 473-486.

Barker, D., and A. Milburn (1984) Development and regeneration of mammalian muscle spindles. Sci. Prog. (Oxford) 69: 45-64.

Bondok, A. A., and F. M. Sansone (1984) Retrograde and transganglionic degeneration of sensory neurons after a peripheral nerve lesion at birth. Exp. Neurol. 86: 322-330.

Ebendal, T., L. Olson, and A. Seiger (1983) The level of nerve growth factor (NGF) as a function of innervation. Exp. Cell Res. 148: 311317.

Ebendal, T., L. Olson, A. Seiger, and K.-O. Hedlund (1980) Nerve growth factors in the rat iris. Nature 286: $25-28$.

Hnik, P., and J. Zelená (1961) Atypical spindles in reinnervated rat muscles. J. Embryol. Exp. Morphol. 9: 456-467. 
Hopkins, W. G., and J. R. Slack (1984) Effect of nerve growth factor on intramuscular axons of neonatal mice. Neuroscience 13: 951-956.

Jenq, C.-B., C. E. Hulsebosch, R. E. Coggeshall, and J. R. Perez-Polo (1984) The effects of nerve growth factor and its antibodies on axonal numbers in the medial gastrocnemius nerve of the rat. Brain Res. 299: 9-14.

Korsching, S., and H. Thoenen (1985) Nerve growth factor supply for sensory neurons: Site of origin and competition with the sympathetic nervous system. Neurosci. Lett. 54: 201-205.

Kuno, M., Y. Miyata, S. Homma, and M. Ogawa (1985) Nerve growth factor enhances central synaptic function of Ia sensory neurons. Neurosci. Res. 2: 275-280.

Landon, D. N. (1972) The fine structure of developing muscle spindles in the rat. J. Anat. 111: 512-513.

Mackenson-Dean, C. A., R. S. Hikada, and T. M. Frangowlakis (1981) Formation of muscle spindles in regenerated avian muscle grafts. Cell Tissue Res. 217: 37-41.

Marchand, E. R., and E. Eldred (1969) Postnatal increase of intrafusal fibers in the rat muscle spindle. Exp. Neurol. 25: 655-676.

McArdle, J. J., and F. M. Sansonc (1977) Re-innervation of fast and slow twitch muscle following nerve crush at birth. J. Physiol. (Lond.) 271: $567-586$.

Milburn, A. (1973) The early development of muscle spindles in the rat. J. Cell Sci. 12: 175-195.

Milburn, A. (1984) Stages in the development of cat muscle spindles. J. Embryol. Exp. Morphol. 82: 177-216.

Miyata, Y., Y. Kashihara, S. Homma, and M. Kuno (1986) Effects of nerve growth factor on the survival and synaptic function of la sensory neurons axotomized in neonatal rats. J. Neurosci. 6: 2012-2018.

Schiaffino, S., and S. Pierobon Bormioli (1976) Morphogenesis of rat muscle spindles after nerve lesion during early postnatal development. J. Neurocytol. 5: 319-336.

Werner, J. K. (1973a) Duration of normal innervation required for complete differentiation of muscle spindlcs in ncwborn rats. Exp. Neurol. 41: 214-217.
Werner, J. K. (1973b) Mixed intra- and extrafusal muscle fibers produced by temporary denervation in newborn rats. J. Comp. Neurol. 150: 279-301.

Yip, H. K., and E. M. Johnson (1984) Developing dorsal root ganglion neurons require trophic support from their central processes: Evidence for a role of retrogradely transported nerve growth factor from the central nervous system to the periphery. Proc. Natl. Acad. Sci. USA 81: 6245-6249.

Yip, H. K., M. Rich, P. A. Lampe, and E. M. Johnson (1984) The effect of nerve growth factor and its antiserum on the postnatal development and survival after injury of sensory neurons in rat dorsal root ganglia. J. Neurosci. 4: 2986-2992.

Zelená, J. (1957) The morphogenetic influence of innervation on the ontogenetic development of muscle spindles. J. Embryol. Exp. Morphol. 5: 283-292.

Zelená, J. (1964) Development, degeneration and regeneration of receptor organs. In Progress in Brain Research, Vol. 13, Mechanisms of Neural Regeneration, M. Singer and P. Schadé, eds., pp. 175-211, Elsevier, Amsterdam.

Zelená, J. (1976) The role of sensory innervation in the development of mechanoreceptors. In Progress in Brain Research, Vol. 43, Somatosensory and Visceral Receptor Mechanisms, A. Iggo and O. B. Ilynsky, eds., pp. 59-64, Elsevier, Amsterdam.

Zelená, J., and P. Hnik (1963) Effect of innervation on the development of muscle receptors. In The Effect of Use and Disuse on Neuromuscular Functions, E. Gutmann and P. Hnik, eds., pp. 95-109, Elsevier, Amsterdam.

Zelená, J., and T. Soukup (1973) Development of muscle spindles deprived of fusimotor innervation. Z. Zellforsch. 144: 435-452.

Zelená, J., and T. Soukup (1974) The differentiation of intrafusal fiber types in rat muscle spindles after motor denervation. Cell Tissue Res. 153: 115-136. 